\title{
Effects of an exercise and stress management program on cardiac patients' psychosocial and vocational status: Preliminary study
}

\author{
MICHAEL T.C. LIANG, PHD \\ MARIO D. GARCIA, MD \\ LORING MCALLISTER, PHD
}

To document the benefits of a combined cardiac stress management (CSM) and exercise training (ET) program for cardiac patients, 80 consecutive postMI and bypass surgery patients were studied. It was anticipated that a CSM-ET program would enhance psychologic recovery from cardiac illness, improve functional capacity, and increase the rate of work resumption. All patients participated in both the CSM and ET phases of the program. No randomly selected control group was included for comparison. At the conclusion of the program, a psychosocial questionnaire documented the changes. The combination program appears to have promoted favorable therapeutic results, as detailed in the report.

Three general classes of psychologic stressgeneral dissatisfaction in life and acute and chronic stressful life events - are associated with coronary heart disease (CHD). In addition, type-A personality behavior has been correlated positively with CHD. ${ }^{2,3}$ Also, these persons frequently experience dissatisfaction with their level of education, interpersonal relations, marital relations, ${ }^{3,4}$ and jobs. ${ }^{1}$

Hackett and Cassem ${ }^{5}$ observed that cardiac patients admitted into a hospital's coronary care unit often exhibit heightened states of anxiety and denial during the first two days, with the peak in depression occurring on the third and fourth days.
During the first month after discharge, these patients frequently have physical weakness, fear of sexual arousal, disturbed sleep, anxiety, and depression. ${ }^{6}$ These symptoms are the most common noncardiac causes of persistent "invalidism." If marked deconditioning is allowed to develop in cardiac patients before or after discharge, excessive psychologic maladjustment may ensue.

Myocardial infarction (MI) diminishes cardiac function, which results in a reduction of work capacity and exercise tolerance. ${ }^{7}$ This physical impairment can influence the patient's quality of life and decision to return to work. The cardiac rehabilitation program is designed to restore and maintain the patient's physiologic, psychosocial, and vocational status.

The purpose of this descriptive study was to document the psychosocial, vocational, and sexual adjustment of cardiac patients. We anticipated that a combined cardiac stress management (CSM) and exercise training (ET) program would enhance cardiac patients' psychologic recovery from their illness and improve their functional capacity, submaximal work output, and work resumption rate. The CSM model was established as a pilot treatment program in addition to the cardiac ET program, which was based in a community hospital.

Random selection of patients or exclusion of others as untreated coronary controls was not practical. Patients paid a small fee for each ET session and were not charged for the CSM program. Under these circumstances, patients served as their own controls. 


\section{Material and methods}

During a two-year period, 116 consecutive post-MI and coronary artery bypass graft surgery (CABGS) patients who had been referred to our phase 2 outpatient (hospital-based) cardiac rehabilitation program were recruited to participate in the study.

A patient with the following medical history was eligible for the study: (1) documented transmural MI, as evidenced by pathologic $\mathrm{Q}$ waves on a 12 lead ECG or elevation of cardiac enzyme levels consistent with MI during the hospital stay; or (2) CABGS.

Patients who had one or more of the following health history, vocational status, or physical characteristics were excluded from the study: inability to pedal a cycle ergometer or walk on a treadmill, leg pain secondary to claudication, atrial fibrillation or flutter, ventricular tachycardia or fibrillation, uncontrolled ventricular dysrhythmia, thirddegree or complete heart block, severe aortic stenosis, unstable angina, acute infection or pericarditis, congestive heart failure, or retirement from occupational work or housework.

A total of 80 patients met the admission criteria and gave informed consent to participate in the study. Of these, 57 ( 53 men, four women) were postMI patients and 23 ( 20 men, three women) had undergone CABGS.

\section{Cardiac stress management program}

Prior to attending the CSM program, the patient completed the Minnesota Multiphasic Personality Inventory (MMPI). No repeat MMPI testing was done at the end of the program, because no significant MMPI profile changes were expected in such a short period (10 weeks) of CSM activity.

Psychosocial (Fig 1) and vocational (Fig 2) questionnaires were completed by the patients without disclosing their identities at the conclusion of the 26 -week cardiac ET program. The questionnaires were designed to assess the patient's attitudes toward post-MI or post-CABGS lifestyle adjustment in the psychosocial and vocational domains. The questionnaire included self-perceived mood changes, health status, marital relations, sexual activity, and work resumption status. The questions were designed to elicit definitive and closedend answers. The patients were asked to respond to all questions, if applicable, and to give honest and accurate answers.

A ten-week CSM program was designed and conducted by a trained counselor and a rehabilitation nurse. It consisted of four group sessions held weekly, each of $11 / 2$ hours' duration, one or two individual sessions (held weekly, each of one hour's duration), and four or five self-monitored practice sessions. Four to six patients and their spouses formed a CSM group. The program dealt specifically with stress, values, communication, family relationships, loss process, and feelings. In addition, neuromuscular relaxation techniques were introduced to help cope with stress and tension.

Session 1 of the group activity focused on stress, with specific emphasis on CHD. This session centered around the need for specific, consistent efforts to adjust to a particular area of stress. The patients were encouraged to develop realistic perspectives concerning what they could and could not change in their lives. A brief description of type-A behavior was presented. In this respect, patients were assisted in making decisions on when and how to minimize some of their self-imposed demands, expectations, and worries.

Session 2 was concerned with individual values. The patients and their spouses were directed to reassess what they considered important at this stage of their life. Illness and its consequent need for change provided people with an opportunity to update, clarify, personalize, and choose their own values, and to see how their actual behavior effectively coincided with their own values.

Session 3 dealt with relationships and communication. Participants were asked to observe some of their needs, which could become known and met in the context of a relationship and in communication with another person. A review of five basic human needs (belonging, achievement, recognition, understanding, and love) were presented. The importance of spouse and family members' involvement in rehabilitation and plans for preventive health was emphasized. The characteristics of healthy relationships were reviewed and discussed.

Session 4 focused on feelings, including the loss process and anger. The classic loss process, as described by Kubler-Ross, ${ }^{8}$ was utilized to assist participants in understanding periods of stress when what was lost might be a controlling factor in one's life.

During the self-monitored practice sessions, worksheets were used to collect information regarding the patient's desire to modify lifestyle, to aid in clarifying points of confusion, and to reinforce positive behavioral changes.

\section{Exercise training program.}

The ET consisted of 78 exercise sessions (three weekly sessions for 26 weeks). Equipment included six arm and leg circuit training stations (arm cranking, rowing, shoulder wheeling, leg cycling, treadmill walking, and stairs climbing). ${ }^{9}$ The circuit training alternated between arm and leg exercises, and each exercise lasted four minutes. 
1. How do you feel about your health in general?

Better (3) Same as Before (2) Worse (1)

2. How do you feel about your heart condition?

Better (3)_ Same as Before (2)_ Worse (1)

3. If you take medications for your heart condition, are they helping you?

Yes No Making worse

4. Compared to before cardiac rehabilitation, how is your mood now?

Good (3) Same as Before (2) Worse (1)

5. Compared to before cardiac rehabilitation, how is your marriage in general?

Better (3) Same as Before (2) Worse (1)

6. Compared to before cardiac rehabilitation, how is your sex life? Increased (3) Same As Before (2)

Decreased (1) Stopped Altogether (0)

7. If your sexual activity has been reduced or stopped, is this due to your heart condition?

Yes No Other Reason

8. If it is due to reasons other than your heart condition, please give other reason(s).

Reasons 
Complete this questionnaire according to the following instructions:

A. If you are WORKING, answer questions 1 to 5 only

B. If you are NOT WORKING or have not worked since your illness, answer questions 6 to 13 only

1. I am now working Yes (1) No (2)

2. I work Full time (1) Part time (2) 2a. Hours per week Hours per week

3. My job is:

4. This is the same job I had before my illness Yes (1) No (2) 4a. If yes, was it changed in some way so that you can work with no or less difficulty? Yes (1) No (2)

4b. If changed, was it changed to a lighter and less stressful job? Yes (1) No (2)

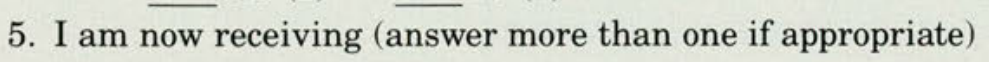

Social security benefits

Veteran's pension

State or county assistance

Workman's compensation

Insurance benefits

Private pension

\begin{tabular}{rr} 
Yes (1) & No (2) \\
Yes (1) & No (2) \\
Yes (1) & No (2) \\
Yes (1) & No (2) \\
Yes (1) & No (2) \\
\hline Yes (1) & No (2)
\end{tabular}

For staff use only

Other:

6. I am not working now ___ Yes (1) __ No (2)

7. Before my illness, I worked for about__ months
8. I worked Full time (1) Part time (2) 8 a. Hours per week

9. My job was:

10. I am not working now because:

Of my health problem (1)

I retired (2)

I I am looking for a different job (3)

I was laid off (4)

I w was fired Other:

11. I would like to return to work Yes (1) No (2)

12. I am now receiving (answer more than one if appropriate) Social security benefits

Veteran's pension

$\begin{array}{rr}\text { Yes (1) } & \text { No }(2) \\ \text { Yes (1) } & \text { No }(2)\end{array}$

State or county assistance Hour per week Yes (1) No (2)

Workman's compensation Insurance benefits Private pension Other:

$\begin{array}{rr}\text { Yes (1) } & \text { No (2) } \\ \text { Yes (1) } & \text { No (2) } \\ \text { Yes (1) } & -\quad \text { No (2) }\end{array}$

13. I would like to see a vocational rehabilitation counselor Yes (1) No (2) 
and at the completion of the ET program). A modified Naughton GXT protocol ${ }^{10}$ was used to obtained the PHR and functional capacity for each patient. This protocol began with an initial workload of 2.5 $\mathrm{mph}$ at $0 \%$ grade, which was raised $3.5 \%$ every three minutes. Throughout the test, the treadmill speed was held constant at $2.5 \mathrm{mph}$.

The cycle ergometry WC test protocol began with an initial workload of $150 \mathrm{kgm} / \mathrm{min}$ for women or $300 \mathrm{kgm} / \mathrm{min}$ for men and a pedaling speed of 50 rpm. Subsequent cycle work was raised $150 \mathrm{kgm} /$ min every four minutes to elicit a submaximal heart rate equal to $85 \%$ of the PHR obtained from the GXT.

The functional capacity, expressed in standard MET units, was determined from highest treadmill speed and percent grade of the GXT test, by using the equation described by the American College of Sports Medicine. ${ }^{10}$ The MET is defined as multiples of the resting metabolic rate ( $1 \mathrm{MET}=$ $3.5 \mathrm{ml} 0_{2}$ per $\mathrm{kg}$ of body weight per minute). The submaximal cycle WC test was expressed in relative work output (that is, $\mathrm{kgm} / \mathrm{min} \times \mathrm{kg}$ ).

Student's t-test was used to analyze the physiologic and MMPI data for statistical significance. For analysis of the psychosocial data, we used ordinal scale of measurement, which ranked observations according to whether the patient had more, less, or the same amount of a variable characteristic following participation in the CSM program. Chisquare testing was used to analyze psychosocial data. The 0.05 probability level was used for all tests of statistical significance.

\section{Results}

Clinical histories of all patients are presented in Table 1 . As a group, 57 patients $(71 \%)$ experienced various degrees of anginal pain. Seventy-three (91\%) were men and seven $(9 \%)$ were women. The mean age of the patients was 57.9 years (range, 37 to 63 years).

At the conclusion of this study, 35 patients (44\%) perceived that their personal mood had improved, and $28(35 \%)$ felt the same as before their MI or CABGS (Table 2). However, 17 patients (21\%) experienced mood change for the worse. Regarding health, $37(46 \%)$ perceived that it had improved, and $26(33 \%)$ felt the same as before. Again, 17 patients $(21 \%)$ felt that their health had worsened. Chi-square statistics showed that the responses to the questions on mood change and health status were significantly different $(P<.05)$, with a greater number of patients feeling better than before.

When questions were asked about marital relationships other than sexual activity, the following results were revealed: 15 patients (19\%) felt hap-

\begin{tabular}{|c|c|c|c|}
\hline Cardiac history & $\begin{array}{c}\text { Total } \\
(\mathrm{N}=80)\end{array}$ & $\begin{array}{c}\text { Men } \\
(\mathrm{N}=73)\end{array}$ & $\begin{array}{r}\text { Women } \\
(\mathrm{N}=7)\end{array}$ \\
\hline \multicolumn{4}{|l|}{ Myocardial infarction } \\
\hline With angina pectoris* & $36(63 \%)$ & $34(64 \%)$ & $2(50 \%)$ \\
\hline \multirow[t]{2}{*}{ Without angina pectoris } & $21(37 \%)$ & $19(36 \%)$ & $2(50 \%)$ \\
\hline & $57(100 \%)$ & $53(100 \%)$ & $4(100 \%)$ \\
\hline \multirow{4}{*}{$\begin{array}{l}\text { CABGS } \\
\text { With angina pectoris* } \\
\text { Without angina pectoris }\end{array}$} & & & \\
\hline & $21(91 \%)$ & $18(90 \%)$ & $3(100 \%)$ \\
\hline & $2 \quad(9 \%)$ & $2(10 \%)$ & $0 \quad(0 \%)$ \\
\hline & $23(100 \%)$ & $20(100 \%)$ & $3(100 \%)$ \\
\hline
\end{tabular}

Total patients with angina pectoris: $57(71 \%)$.

pier than before their MI or CABGS, $58(72 \%)$ felt the same, and seven (9\%) felt that their marital relationship had deteriorated. When asked about their sexual activity, only 58 patients $(73 \%)$ answered the question. Fourteen patients $(24 \%)$ had stopped sexual activity since their illness. Reasons for stopping were as follows: "old age" $(\mathrm{N}=2)$, divorced or separated $(\mathrm{N}=2)$, widowers $(\mathrm{N}=2)$, no known reason $(\mathrm{N}=3)$, and poor cardiac condition $(\mathrm{n}=5)$. Interestingly, two $(4 \%)$ responded that their sexual activity had improved, $32(55 \%)$ said it was the same, and $10(17 \%)$ said it was reduced. Chi-square analysis revealed that a significantly greater $(P<.05)$ number of patients felt that their marital relation and sexual activity were the same as before.

The mean scores of the ten clinical scales on the MMPI are presented in Fig 1 (male patients) and Fig 2 (female patients). Because there was no control group, two groups of patients of similar age range who were hospitalized for illnesses largely unrelated to cardiac disease were obtained from Swenson and associates'12 study. These two groups are referred to as noncardiac male and female groups. When compared to the noncardiac male group, the following MMPI scales obtained from our male patients were significantly elevated $(P$ $<.05)$ : hypochondriasis, depression, hysteria, psychasthenia, and schizophrenia. When compared to the noncardiac female group, hysteria was the only scale that was significantly higher $(P<.05)$ in our female patients.

The physiologic data for both sexes revealed that $81.3 \%$ of the patients improved their functional capacity (Table 3 ). Of the 80 patients, 15 (19\%) responded minimally (from an average of 2.9 to 4.2 METs) or negatively (from an average of 7 to 5.9 METs). Consequently, these patients were grouped as nonrespondents for the purpose of discussion.

The difference in functional capacity between men and women was not significant. Female patients showed a $52 \%$ improvement in functional ca- 


\begin{tabular}{|c|c|c|c|c|c|c|}
\hline Parameter & $\mathrm{N}$ & Improved & Same & Worse & Stopped & $\begin{array}{c}\text { Chi-square } \\
\text { value }\end{array}$ \\
\hline Mood & 80 & $\begin{array}{c}35 \\
(44 \%)\end{array}$ & $\begin{array}{c}28 \\
(35 \%)\end{array}$ & $\begin{array}{c}17 \\
(21 \%)\end{array}$ & - & $\begin{array}{c}6.174 \\
(P<05)\end{array}$ \\
\hline Health & 80 & $\begin{array}{c}37 \\
(46 \%)\end{array}$ & $\begin{array}{c}26 \\
(33 \%)\end{array}$ & $\begin{array}{c}17 \\
(21 \%)\end{array}$ & - & $\begin{array}{c}7.523 \\
(P<05)\end{array}$ \\
\hline Marital relation & 80 & $\begin{array}{c}15 \\
(19 \%)\end{array}$ & $\begin{array}{c}58 \\
(72 \%)\end{array}$ & $\begin{array}{c}7 \\
(9 \%)\end{array}$ & $\overline{-}$ & $\begin{array}{c}56.417 \\
(P<.05)\end{array}$ \\
\hline Sexual activity & 58 & $\begin{array}{c}2 \\
(4 \%)\end{array}$ & $\begin{array}{c}32 \\
(55 \%)\end{array}$ & $\begin{array}{c}10 \\
(17 \%)\end{array}$ & $\begin{array}{c}14 \\
(24 \%)\end{array}$ & $\begin{array}{c}33.308 \\
(P<.05)\end{array}$ \\
\hline
\end{tabular}

\begin{tabular}{|c|c|c|c|c|c|c|c|c|c|c|}
\hline \multirow[b]{2}{*}{ Subjects } & \multirow[b]{2}{*}{$\mathrm{N}$} & \multirow[b]{2}{*}{$\overline{\mathrm{X}} / \mathrm{SD}$} & \multicolumn{4}{|c|}{ Functional capacity (MET) } & \multicolumn{4}{|c|}{ Relative work output (kgm/kg/min) } \\
\hline & & & $\begin{array}{l}\text { Before } \\
\text { program }\end{array}$ & $\begin{array}{l}\text { After } \\
\text { program }\end{array}$ & $\begin{array}{l}\text { Percent } \\
\text { change }\end{array}$ & Significance & $\begin{array}{l}\text { Before } \\
\text { program }\end{array}$ & $\begin{array}{l}\text { After } \\
\text { program }\end{array}$ & $\begin{array}{l}\text { Percent } \\
\text { change }\end{array}$ & Significance \\
\hline \multirow[t]{2}{*}{ Men } & \multirow[t]{2}{*}{73} & $\overline{\mathrm{X}}$ & 5.0 & 8.3 & 76.5 & \multirow[t]{2}{*}{$P<.05$} & 5.77 & 7.79 & $35.0^{\mathrm{a}}$ & \multirow[t]{2}{*}{$P<.01$} \\
\hline & & SD & 1.3 & 2.2 & 65.4 & & 1.39 & 1.59 & 28.8 & \\
\hline \multirow[t]{2}{*}{ Women } & 7 & $\overline{\mathrm{X}}$ & 5.2 & 7.7 & 52.2 & \multirow[t]{2}{*}{$P<.05$} & 5.57 & 6.46 & 17.6 & \multirow[t]{2}{*}{ NS } \\
\hline & & SD & 2.2 & 2.3 & 42.1 & & 1.25 & 1.50 & 23.4 & \\
\hline \multirow[t]{2}{*}{ All } & 80 & $\overline{\mathrm{X}}$ & 5.0 & 8.0 & 68.9 & \multirow[t]{2}{*}{$P<.05$} & 5.72 & 7.46 & 33.4 & \multirow[t]{2}{*}{$P<.01$} \\
\hline & & SD & 1.5 & 2.2 & 34.3 & & 1.36 & 1.57 & 27.5 & \\
\hline \multirow[t]{2}{*}{ Nonresponders } & 15 & $\overline{\mathrm{X}}$ & 4.4 & 5.0 & $20.5^{b}$ & \multirow[t]{2}{*}{ NS } & 5.52 & 6.35 & $13.1^{\mathrm{b}}$ & \multirow[t]{2}{*}{ NS } \\
\hline & & SD & 1.7 & 1.0 & 34.3 & & 1.57 & 1.51 & 7.6 & \\
\hline $\begin{array}{l}\text { Significant differ } \\
\text { Significant differ } \\
\overline{\mathrm{X}}=\text { mean value; }\end{array}$ & $\begin{array}{l}\text { e }(P \\
=\mathrm{st}\end{array}$ & $\begin{array}{l}\text { betwee } \\
\text { betweer } \\
\text { ad devia }\end{array}$ & $\begin{array}{l}\text { the sexes. } \\
\text { the respon } \\
\text { ion; and NS }\end{array}$ & $\begin{array}{l}\text { ders and th } \\
S=\text { not sig }\end{array}$ & $\begin{array}{l}\text { nonrespon } \\
\text { icant. }\end{array}$ & ders. & & & & \\
\hline
\end{tabular}

pacity, while male patients exhibited a $77 \%$ gain. Both gains were significantly higher $(P<.05)$ than pretraining values. For both sexes combined, the WC at $85 \%$ of PHR showed a mean gain of $33 \%$ $(P<.01)$ following the ET program. Female patients demonstrated an $18 \%$ improvement in submaximal WC, while male patients showed a $35 \%$ gain $(P<.05)$. The difference between the sexes was significant $(P<.05)$.

Sixty-nine patients $(86 \%)$ either returned to work $(\mathrm{N}=63)$ or were able to work but chose not to $(\mathrm{N}=6)$ (Table 4). The period between the cardiac event and re-employment ranged from two to five months (mean, four months). Eleven patients (14\%) were classified as medically disabled for work resumption. The decision that a patient was disabled was determined independently by one of the investigators, who was a consulting physician for the Minnesota Department of Social Security and Disability. Fifty-five male patients returned to fulltime work at their previous jobs with minimal task modifications, and two returned to part-time work. Six female patients returned to their same previous work (at home).

\section{Discussion}

There is a lack of research findings supporting the assumption that psychologically (defined in terms of stimulus conditions and response), patients with MI differ from those who have undergone CABGS. Soloff ${ }^{13}$ compared medically managed and surgically managed cardiac patients and their psychologic make-ups. Among the psychologic parameters measured (for example, Profile of Mood States (POMS) and Hackett-Cassem Denial Scale) prior to entry into their cardiac exercise program, only mood disturbance was significantly high in the medically managed patients. These patients experienced greater mood improvement after six weeks of exercise rehabilitation compared to the surgically managed patients.

Our MMPI data revealed no marked differences $(P>.50)$ between the post-MI and post-CABGS patients. Based on these sources of information, it was reasonable to combine the psychosocial and vocational data obtained from the post-MI and postCABGS patients and analyze them as a single group.

Because of marked MMPI profile difference $(P$ $<.05$ ) between male and female patients, their MMPI results were discussed separately (Figs 3,4). According to the MMPI interpretation (made by one of the investigators), male patients reacted to cardiac trauma with greater emotional and psy- 
chologic upheaval and distress. Specifically, male patients tended to exhibit significant levels of somatic concern, depression, anxiety, tension, mental confusion, and, possibility, alienation. At the same time, they also manifested tendencies toward denial and repression. These observations support the findings of Ruskin and coworkers. ${ }^{14}$ Conversely, female patients experienced fewer emotional and mental disturbances. The relatively small number of women in the present sample limited the ability to generalize about the results. However, the MMPI profile of the male patients can be interpreted with some certainty; that is, the cardiac trauma represented more of an ego threat to them than to the female patients.

Using a control group, Saunamaki ${ }^{15}$ observed a $32 \%$ gain in maximal work output at six months' follow-up, while his ET group showed a significant gain of $66 \%$. His results were compatible with data obtained in the present study regarding maximal functional capacity. The improvement in functional capacity exhibited by the patients suggested that enhanced cardiovascular fitness resulted from the exercise training. This cardiovascular adaptation may be interpreted as peripheral regulatory alterations without implying improvement in myocardial performance. ${ }^{16}$ For example, increased stroke volume and muscle blood flow observed after exercise training may suggest a reduced peripheral resistance or afterload that is not necessarily caused by improved myocardial contractility. The enhanced functional capacity was accomplished by a significant gain in submaximal work output. Because WC was measured at $85 \%$ of PHR, the gain of $33 \%$ was lower than that of Saunamaki's. ${ }^{15}$

Despite the fact that the patients trained at $85 \%$ of their symptom-limited PHR and the average compliance rate was $83 \%$, not all of the patients responded to exercise training. The clinical histories of these nonresponders are presented in Table 5 . The following factors appear to contribute to this nonresponse to exercise training: persistent angina pectoris $(100 \%)$, significant ST-T segment depression $(93 \%)$, ventricular arrhythmias (93\%), and combined MI and CABGS $(60 \%)$. Their training compliance rate $(80 \%)$ was $5 \%$ lower than the responders.

Some $19 \%$ to $21 \%$ of our patients responded negatively to the CSM-ET program. Wenger ${ }^{17}$ reported that approximately $20 \%$ of cardiac patients may not respond to an ET program. She believed that the primary cause was the severity of these patients' cardiac problems secondary to abnormal postevent psychosocial adjustment. Because our psychosocial and vocational questionnaire responses were anonymous, we were unable to correlate these patients with the 15 nonresponders.

Physiologic, psychologic, or economical factors or a combination may influence a patient's decision to return to a gainful employment or to take early retirement. Six of the employable male patients decided not to return to work because they received supplemental income from their social security benefit, insurance compensation, or company benefits. Some of them received compensation from multiple sources greater than their regular wages. The incentive for these patients to return to work was minimal.

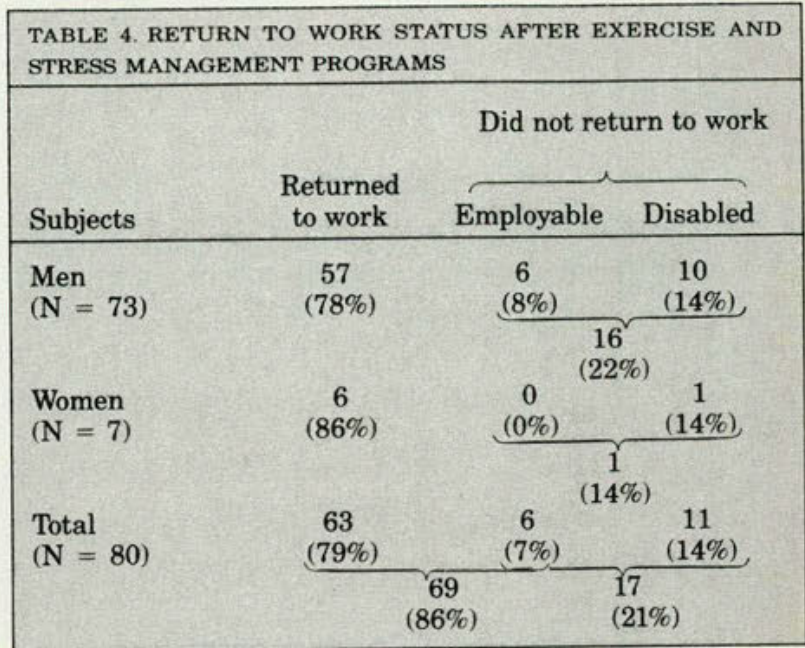

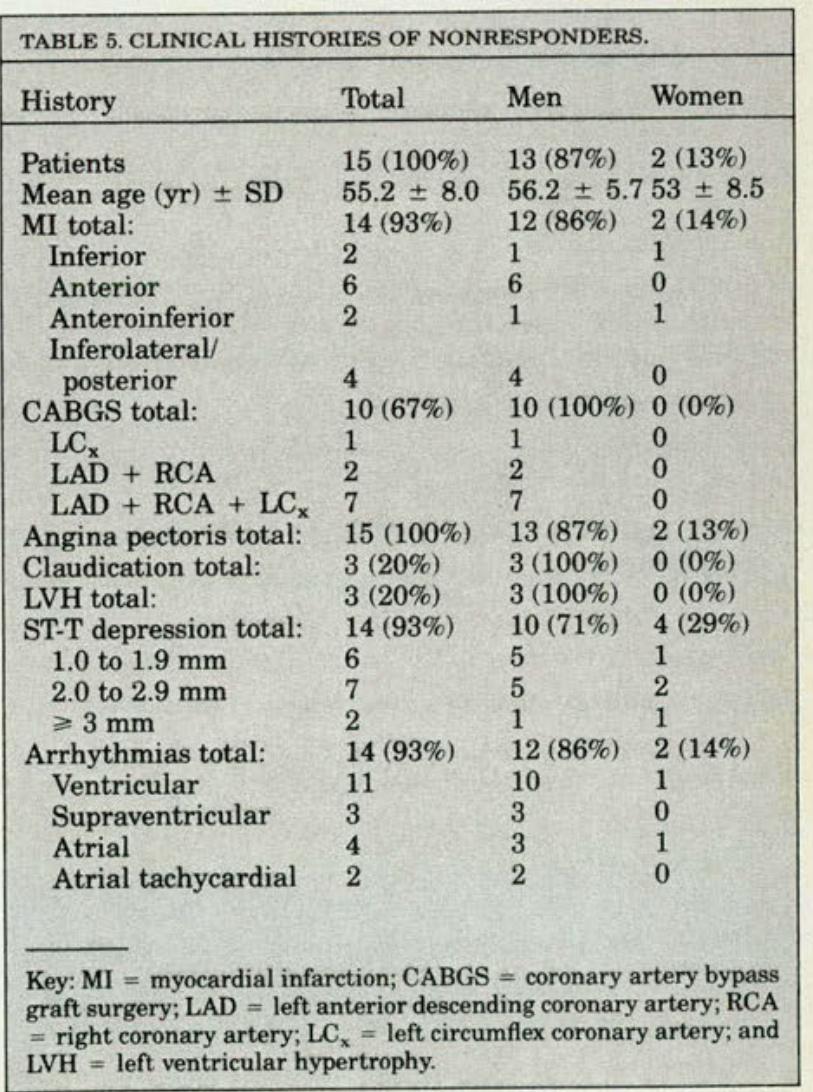




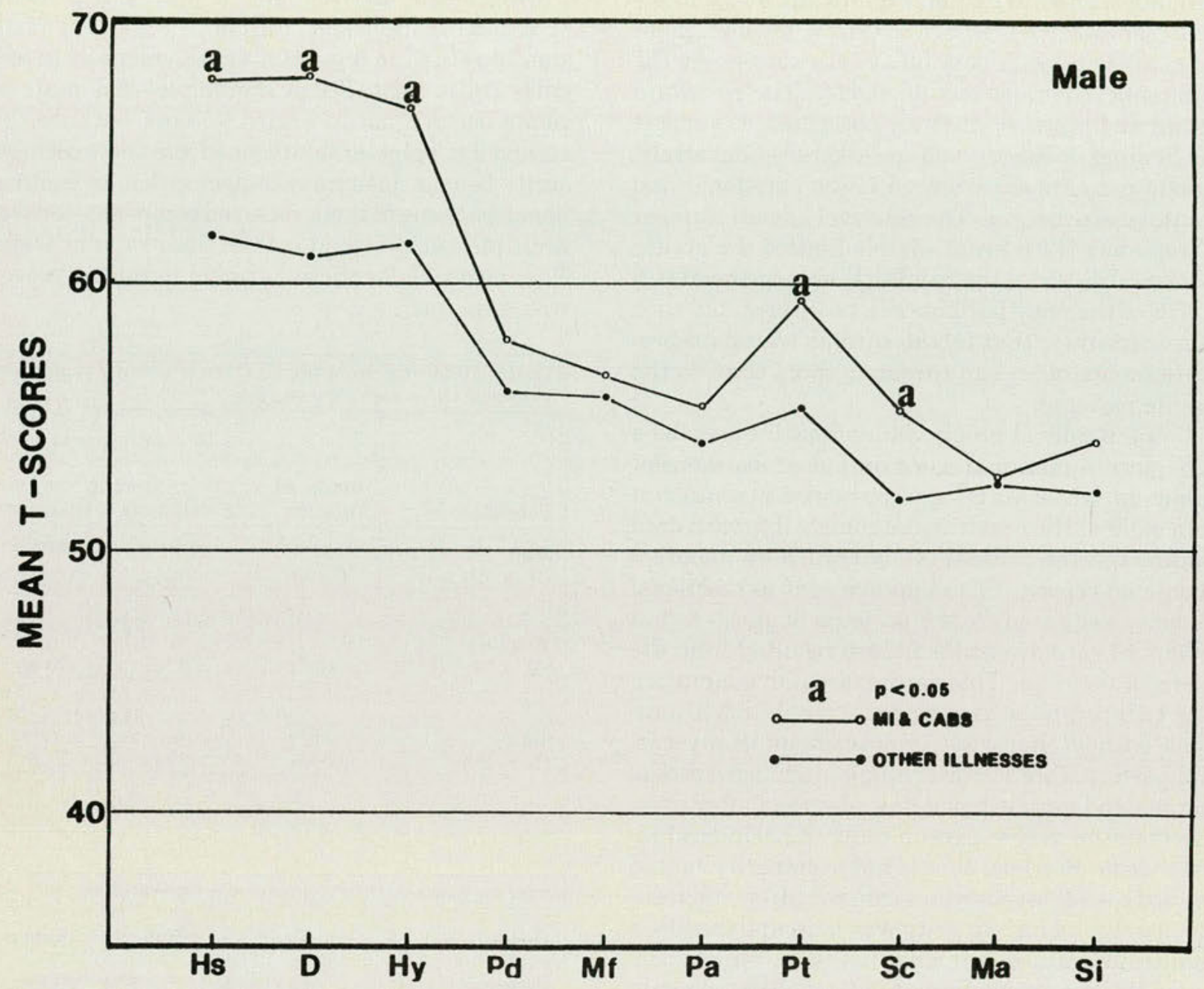

Figs 3 and 4. MMPI scores of male (Fig 3) and female (Fig 4) cardiac patients. Key: Hs = hypochondriasis; D = depression; Hy = hysteria $; \mathrm{Pd}=$ psychopathic deviant $; \mathrm{Mf}=$ masculinity-femininity; $P a=$ paranoia $; \mathrm{Pt}=$ psychesthenia $;$ Sc = schizophrenia ; $M a=$ hypomania $;$ and $S i=$ social introversions.

Thockloth and associates ${ }^{18}$ reported that after a three-month exercise rehabilitation program, $90 \%$ of their patients had returned to work, compared to $82 \%$ who had no exercise program. In Israel, Kellermann ${ }^{19}$ reported that $85 \%$ of his postMI patients returned to work after four months of exercise rehabilitation. Our work resumption rate would had been compatible with Kellermann's if the six $(7 \%)$ employable patients had resumed work.

These authors also observed that delays in returning to work (longer than three months after the onset of illness) are due to anxiety, fear, dependency, lack of confidence, or lack of financial incentive. Kellermann ${ }^{19}$ found that nonreturn to work was due to significant angina pectoris, fear, medical misinformation, or psychologic reasons. We observed that severity of cardiac problem, recurrence of cardiac-related symptoms (angina, dyspnea, arrhythmias), and lack of financial incentive were the primary factors contributing to the failure to return to work.

It is reasonable to speculate that regular contacts with health care professionals by the patients while attending the ET and CSM sessions may have a positive influence on the patient's psychologic component of recovery. It also is possible that improved cardiovascular fitness and physical work capacity, which were the direct results of ET, ${ }^{7,15,16}$ may be perceived by the patient as improved health. These relationships were not confirmed in the present study. However, McPherson and 


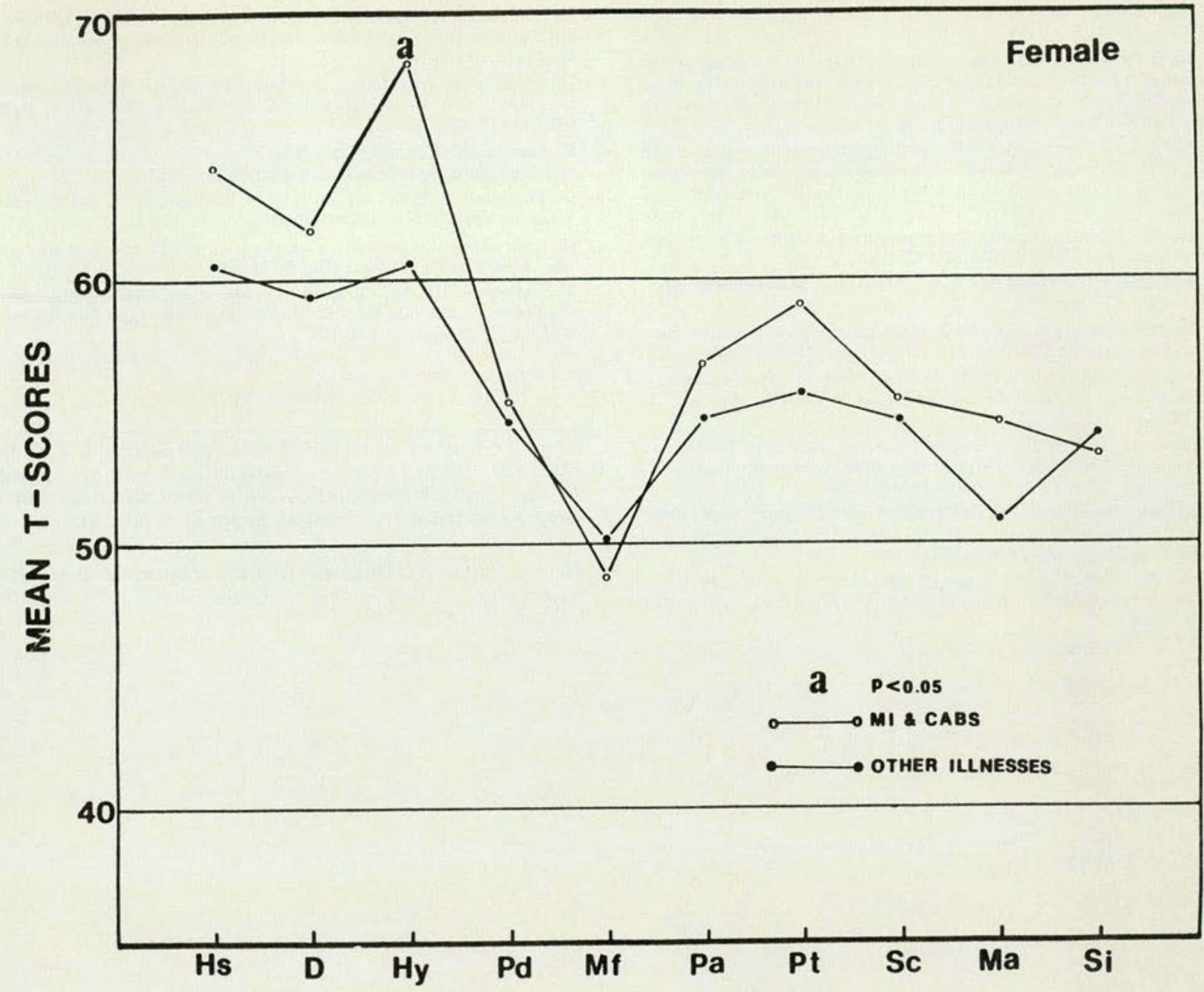

coauthors ${ }^{20}$ observed that after exercise training, cardiac patients exhibited an improved sense of well-being as physical discomfort diminished. Soloff ${ }^{13}$ observed that improvements in mood were independent of improvement in exercise capacity.

\section{Conclusions}

In a clinical rehabilitation setting, the combined CSM and ET program described in this study appeared to enhance favorable therapeutic outcomes in terms of personal mood changes, health status, marital relations, and sexual activity. The ideal study design would include a control group that underwent ET without a CSM program. Because our study did not include a randomly selected control group and was based on a small sample size of post-MI and post-CABGS patients, caution is required in extrapolating the psychosocial and voca- tional data to the general cardiac rehabilitation population. We hypothesize that the improvement in cardiovascular fitness and submaximal work capacity combined with the subjective feelings of wellbeing, better mood, and maintained marital relations and sexual activity may exert a positive influence on the patient's decision to return to gainful employment. Follow-up studies are needed to determine whether a group of patients who participate in an ET program without CSM treatment would exhibit similar psychosocial and vocational benefits.

1. Glass DC: Behavior Patterns, Stress and Coronary Disease. Hillside, NJ, Lawrence Erlbaum Associates, Inc, 1977, pp 12-22.

2. Friedman M, Rosenman RH: Type A Behavior and Your Heart. New York, Alfred A. Knopf, 1974. 
3. Jenkins DC: Psychologic and social precursors of coronary disease. $N$ Engl J Med 1971;284:244-255,307-317.

4. Jenkins DC: Recent evidence supporting psychologic and social risk factors for coronary heart disease. N Engl J Med 1976;294:987-994,10331038.

5. Hackett TP, Cassem NH: Psychological adaption to convalescence in myocardial infarction patients, in Naughton J, Hellerstein HK (eds): Exercise Testing and Exercise Training in Coronary Heart Disease. New York, Academic Press, 1973, pp 253-262.

6. Gulledge AD: Psychological aftermaths of myocardial infarction, in Gentry WD, Williams RB Jr (eds): Psychological Aspects of Myocardial Infarction and Coronary Care, ed 2. St. Louis, CV Mosby Co, 1979, pp 113-130.

7. Bruce RA: The benefit of physical training for patients with coronary heart disease. Am Heart $J$ 1972;84:422-423.

8. Kubler-Ross E: On Death and Dying. New York, MacMillan Publishing $\mathrm{Co}, 1969$.

9. Liang MTC, Garcia M, Zehnder J, et al: A hospital based comprehensive cardiac rehabilitation program. Minn Med 1982;2:107-109.

10. American College of Sports Medicine: Guidelines for Exercise Testing and Prescription, ed 3. Philadelphia, Lea \& Febiger, 1986, pp 21 . 22,157-163.

11. Bergstrom K, Bjernulf A, Erickson J: Work capacity and blood volumes before and after physical training in male patients after a myocar dial infarction. Scand J Rehab Med 1974;6:51-64.

12. Swenson WM, Pearson JS, Osborne D: An MMPI Source Book: Basic Item, Scale, and Pattern Data on 52,000 Medical Patients. Minneapolis, University of Minnesota Press, 1973, p 13.

13. Soloff PH: Medically and surgically treated coronary patients in cardiovascular rehabilitation: A comparative study. Int $J$ Psychiatry Med 1979;9:93-105.
14. Ruskin HD, Stein LL, Sheisky IM, et al: MMPI comparison in patients with coronary heart disease and spouses together with other demographic data. Scand J Rehab Med 1970;2:99-104.

15. Saunamaki KI: Feasibility and effect of physical training with maximum intensity in men after acute myocardial infarction. Scand J Rehab Med 1978;10:155-162.

16. Clausen JP, Trap-Jensen J: Effects of training on the distribution of cardiac output in patients with coronary artery disease. Circulation 1970;42:611-624.

17. Wenger NK: Coronary Care: Rehabilitation After Myocardial Infarction. New York, American Heart Association, 1973.

18. Thockloth $\mathrm{R}$, Ho $\mathrm{SC}$, Wright $\mathrm{H}$, et al: Is cardiac rehabilitation really necessary? Med J Aust 1973;2:669-674.

19. Kellermann JJ: Rehabilitation of patients with coronary heart disease. Prog Cardiovasc Dis 1975;17:303-328.

20. McPherson PD, Paivio A, Wohasz MS, et al: Psychological effects of an exercise program for post-infarct and normal adult men. $J$ Sports Med Phys Fitness 1967;7:95-102.

From the Division of Sports Medicine, Department of Family Medicine, Chicago College of Osteopathic Medicine, Chicago, Ill, and Cardiac Rehabilitation Center, Department of Cardiology, Divine Redeemer Hospital, South St. Paul, Minn.

Reprint requests to Dr Liang, Division of Sports Medicine, Chicago College of Osteopathic Medicine, $5200 \mathrm{~S}$ Ellis Ave, Chicago IL 60615 . 